\title{
Inhalation of stable dust extract prevents allergen induced airway inflammation and hyperresponsiveness
}

\author{
M Peters, M Kauth, J Schwarze, C Körner-Rettberg, J Riedler, D Nowak, C Braun- \\ Fahrländer, E von Mutius, A Bufe, O Holst, the ALEX Study Group
}

See end of article for authors' affiliations

......................

Correspondence to DrM Peters, Department of Experimental Pneumology, Ruhr-University Bochum, Bürkle-de-la-Camp-Platz 1, 44789 Bochum, Germany; marcus.peters@ rub.de

Received 13 July 2005 Accepted 10 October 2005 Published Online First 21 October 2005
Background: Recent epidemiological studies have shown that growing up on a traditional farm provides protection from the development of allergic disorders such as hay fever and allergic asthma. We present experimental evidence that substances providing protection from the development of allergic diseases can be extracted from dust collected in stables of animal farms.

Methods: Stable dust was collected from 30 randomly selected farms located in rural regions of the Alps (Austria, Germany and Switzerland). The dust was homogenised with glass beads and extracted with physiological sodium chloride solution. This extract was used to modulate immune response in a well established mouse model of allergic asthma.

Results: Treatment of mice by inhalation of stable dust extract during sensitisation to ovalbumin inhibited the development of airway hyperresponsiveness and airway eosinophilia upon challenge, as well as the production of interleukin 5 by splenocytes and of antigen specific $\lg G_{1}$ and $\lg E$. Dust extract also suppressed the generation of human dendritic cells in vitro. The biological activity of the dust extract was not exclusively mediated by lipopolysaccharide.

Conclusions: Stable dust from animal farms contains strong immune modulating substances. These substances can interfere with the development of both cellular and humoral immunity against allergens, thus suppressing allergen sensitisation, airway inflammation, and airway hyperresponsiveness in a murine model of allergic asthma.
O ne explanation for the increase in allergic diseases during the last 30 years originates from the "hygiene hypothesis" which proposes that increases in the prevalence of allergic disorders are linked to changes in the microbial burden to which children are exposed in early life. ${ }^{1-4}$ Epidemiological studies have recently shown that growing up on a traditional animal farm can protect from sensitisation to allergens and the development of asthma and hay fever. The exposure of infants to the environment of stables during the first year of life seems to be crucial for this protection. In the search for pathogen derived factors which inhibit the development of allergen sensitisation, many studies have concentrated on lipopolysaccharide (LPS), which can induce allergy protective Thl type immune responses in animal experiments. ${ }^{5-7}$ Interestingly, LPS levels in dust from mattresses of children were inversely related to the frequency of atopic sensitisation and atopic asthma, and overall endotoxin levels were significantly higher in dust from farming than from nonfarming households. ${ }^{2}$ A recent study showed that, in addition to endotoxin, other microbial components such as peptidoglycans were associated with a reduction in non-atopic asthma symptoms. ${ }^{4}$

In animal models of allergen induced asthma, LPS treatment led to Thl dominated immune responses. ${ }^{78}$ Given systemically before sensitisation, LPS reduced both the production of allergen specific IgE and numbers of eosinophils in the bronchial mucosa, demonstrating that the Th2 response normally associated with allergic sensitisation in mice was inhibited. In contrast to these animal models, LPS activation of peripheral blood mononuclear cells in children, who themselves had been exposed to high amounts of endotoxin levels in early childhood, seemed to lead to immune tolerance to LPS. ${ }^{2}$ This finding indicates that downregulation rather than activation of the immune response to bacterial pathogens is associated with protection from allergy. These conflicting results suggest that LPS is probably primarily a marker for microbial burden rather than the principal molecule responsible for the protective effect of the farm environment. It is possible that allergy protection induced by the exposure to a farming environment is linked to the activity of $\mathrm{T}$ regulatory cells (Treg) releasing transforming growth factor $\beta$ (TGF- $\beta$ ) and interleukin (IL)10 and suppressing both Th1 and Th2 immune responses. ${ }^{9}{ }^{10}$

To date there has been no experimental confirmation for the epidemiological observation that exposure to stable dust reduces the risk for allergic diseases. A study was therefore undertaken in which dust was collected from stables of traditional farms, extracted with physiological sodium chloride solution, and tested to determine whether inhalation of this extract could modify allergic responses in a mouse model of acute allergic asthma. The influence of the dust extract on the generation of dendritic cells from human monocytes was also determined in vitro.

\section{METHODS}

\section{Collection of stable dust}

A total of 30 farming households were selected, all located in rural regions of the Alps where the previous field studies were also conducted. ${ }^{12}$ Sediment dust from cattle and goat stables was collected by scraping off all surfaces at a height of

Abbreviations: $A H R$, airway hyperresponsiveness; $\mathrm{BAL}$ bronchoalveolar lavage; IFN- $\gamma$, interferon $\gamma$; IL, interleukin; LPS, lipopolysaccharide; PBS, phosphate buffered saline 


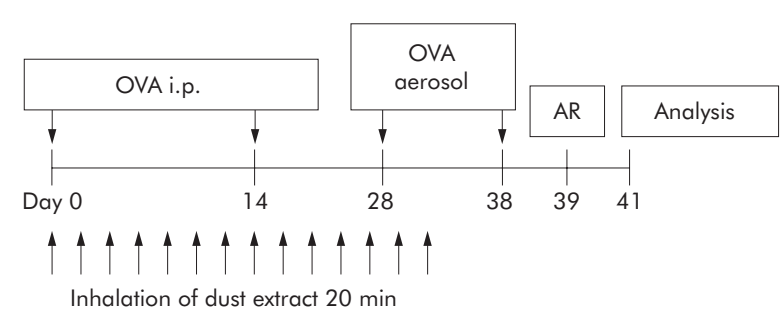

Figure 1 Design of in vivo experiments. OVA i.p. denotes systemic immunisation with ovalbumin adsorbed in aluminum hydroxide. OVA aerosol indicates challenges with $1 \%$ ovalbumin aerosol via the airways. $A R$, airway responsiveness. Analysis indicates harvest of bronchoalveolar lavage fluid cells, serum, and splenocytes for analysis.

0.05-0.15 m (racks, tables, tools) with a metal spatula. From each farm 100-200 g dust was collected and passed through a conventional kitchen sieve. All dust samples were then combined.

\section{Extraction of stable dust}

For homogenisation of the dust, $15 \mathrm{~g}$ of glass beads (0.4$0.6 \mathrm{~mm}$ in diameter) were added to $10 \mathrm{~g}$ dust, double distilled water was added to give a final volume of $70 \mathrm{ml}$, and the sample was homogenised in a Braun MSK homogeniser (B Braun, Melsungen, Germany). Five samples ( =50 g of dust) were combined and extracted with $0.9 \%$ aqueous sodium chloride $(\mathrm{NaCl})$ solution (total volume 5 litres) for 6 hours at $22^{\circ} \mathrm{C}$ with continuous stirring. After centrifugation the dust extract was dialysed against water and then lyophilised.

\section{Animals}

Female BALB/c mice (Charles River, Sulzfeld, Germany) aged 7-8 weeks were used and acclimated to the animal facility for 14 days before the experiments. The animals had access to food and water ad libitum. All experimental procedures were approved by the animal ethics committee at Bezirksregierung Arnsberg.

\section{Sensitisation and airway challenge}

Mice were sensitised by intraperitoneal injection of $20 \mu \mathrm{g}$ ovalbumin (OVA gradeV; Sigma, St Louis, MO, USA) emulsified in $2.2 \mathrm{mg}$ aluminum hydroxide (ImjectAlum; Pierce, Rockford, IL, USA) in a total volume of $200 \mu \mathrm{l}$ on days 1 and 14. On days 28 and 38 mice were challenged via the airways with $1 \%$ OVA aerosol for 20 minutes (fig 1 ) using a PARI-Boy aerosol generator. Controls were injected with aluminum hydroxide alone and challenged with PBS aerosol (non-sensitised).

\section{Treatment of animals with stable dust extract}

Mice were treated with stable dust extract during the sensitisation phase (fig 1). Extract was administered as aerosol generated from a $10 \mathrm{mg} / \mathrm{ml}$ solution. For treatment, the mice were placed in a plexiglass chamber (volume 11 litres) which was connected to a PARI-Boy Turbo jet stream aerosol generator (PARI, Starnberg, Germany) and allowed to inhale the aerosol for 20 minutes. Mice were treated 14 times beginning on the day of the first OVA injection and the last treatment 6 days before the second OVA aerosol challenge (fig 1). Control groups were sensitised as described above and treated 14 times with either phosphate buffered saline (PBS) or $0.8 \mu \mathrm{g} / \mathrm{ml} E$ coli LPS during the sensitization phase. The LPS concentration was chosen to match the concentration in the dust extract detected by Limulus amebocyte lysate assay. The $E$ coli LPS used in the study was purified at Forschungszentrum Borstel.
In stimulation assays with human mononuclear cells it is highly biological active, and induces maximal tumour necrosis factor (TNF) $\alpha$ release at a concentration of $2 \mathrm{ng} /$ $\mathrm{ml}$ and maximal IL- 10 release at $0.4 \mathrm{ng} / \mathrm{ml}$.

\section{Airway responsiveness}

24 hours after the last aerosol challenge airway hyperresponsiveness (AHR) to methacholine aerosol (0, 6, 12, 25 and $50 \mathrm{mg} / \mathrm{ml}$, Sigma) was evaluated in conscious unrestrained mice using whole body plethysmography (Buxco Electronics) by measuring the enhanced pause (Penh). ${ }^{11-13}$ Previous studies have shown that the AHR to methacholine reaches its maximum 24 hours after OVA challenge. ${ }^{12}$ Furthermore, it has been shown that, in this experimental setting, AHR assessed by Penh correlates closely with increases in airway resistance in ventilated animals. ${ }^{12}$

\section{In vitro cytokine production of mouse splenocytes}

Spleens were harvested 3 days after the second aerosol challenge. Single cell suspensions were prepared by mechanical disruption and erythrocytes were lysed. Spleen cells were then cultured at a concentration of $5 \times 10^{6} / \mathrm{ml}$ in complete tissue culture medium (CTCM) (RPMI 1640 with 10\% fetal calf serum (FCS), $2 \mathrm{mM}$ L-glutamine, $100 \mathrm{U} / \mathrm{ml}$ penicillin, $100 \mu \mathrm{g} / \mathrm{ml}$ streptomycin, all from Biochrom, Berlin, Germany). To stimulate specific cytokine production, OVA was added to a final concentration of $50 \mu \mathrm{g} / \mathrm{ml}$. After 48 hours of culture, supernatants were taken and stored at $-80^{\circ} \mathrm{C}$ until analysis. Levels of IL- 5 and IL- 10 were assessed using optEIA kits (BD Biosciences, Heidelberg, Germany) according to the manufacturer's instructions.

\section{Bronchoalveolar lavage (BAL)}

Three days after OVA challenge the lungs were lavaged via a tracheal tube with $2 \times 1 \mathrm{ml}$ PBS and leucocytes in the lavage fluid were counted. After centrifugation, BAL fluid was frozen for further analysis. Cytospin slides of BAL cells were stained with a fast staining procedure (HAEMESchnellfärbung, Labor+Technik Eberhard Lehmann, Berlin, Germany) according to the manufacturer's instructions. The percentages of eosinophils, lymphocytes, and macrophages in BAL fluid samples were determined by light microscopy. At least 300 cells per sample were differentiated by a blinded investigator.

\section{Measurement of OVA specific $\lg G_{1}, \lg G_{2 a}$ and $\lg E$ in serum and BAL fluid}

Blood was collected by tail vein puncture 2 days after the second aerosol challenge. BAL fluid was collected as described above. Levels of OVA specific $\operatorname{IgG}_{1}, \operatorname{IgG}_{2 a}$ and $\operatorname{IgE}$ in serum or BAL fluid were determined by ELISA. Briefly, sample wells of a Nunc maxisorb ELISA plate (Nunc, Wiesbaden, Germany) were coated with $5 \mu \mathrm{g} / \mathrm{ml}$ OVA overnight and then blocked with $1 \%$ bovine serum albumin. After incubation with diluted samples, bound OVA specific antibodies were detected with isotype specific antibodies, rat anti-mouse $I_{g G_{2 a}}$ (clone R19-15) and rat anti-mouse IgG (clone X56), both conjugated to alkaline phosphatase or biotinylated rat anti-mouse IgE (clone R35-72) (all from BD Biosciences). The latter antibody was detected by horseradish peroxidase conjugated extravidin (Sigma). In control experiments isotype specific rat anti-mouse IgE antibody does not cross react with $\operatorname{IgG}_{1}$ or $\operatorname{IgG}_{2 \mathrm{a}}$ isotype. Serum levels of OVA specific $\operatorname{Ig}_{1}$ and $\operatorname{IgE}$ were related to combined standard sera generated in our laboratory and expressed as arbitrary units per $\mathrm{ml}$. Levels of OVA specific $\operatorname{IgG}_{2 \mathrm{a}}$ in $1 / 10$ diluted serum were expressed as optical density measured at a wavelength of $405 \mathrm{~nm}\left(\mathrm{OD}_{405}\right)$. 


\section{Generation of human dendritic cells in vitro}

Human monocyte derived dendritic cells were generated essentially as described elsewhere. ${ }^{14}$ Briefly, mononuclear cells were isolated from the peripheral blood of healthy volunteers by Ficoll-Paque density gradient centrifugation. Monocytes were purified by centrifugal elutriation or adherence to plastic for 2 hours at $37^{\circ} \mathrm{C}$ each yielding similar results. Purified monocytes were cultured at $37^{\circ} \mathrm{C}$ in $5 \% \mathrm{CO}_{2}$ for 7 days at $1 \times 10^{6} / \mathrm{ml}$ in CTCM supplemented with $500 \mathrm{U} /$ $\mathrm{ml}$ recombinant human GM-CSF, $500 \mathrm{U} / \mathrm{ml}$ recombinant human IL-4 (both from PeproTech, London, UK) and with or without $25 \mu \mathrm{g} / \mathrm{ml}$ dust extract or $2 \mathrm{ng} / \mathrm{ml}$ LPS from $E$ coli as a matched control to the LPS content of dust extract. Every other day $50 \%$ of the medium was replaced by fresh prewarmed medium containing the same supplements. To induce maturation, $250 \mathrm{ng} / \mathrm{ml}$ LPS were added on day 6 and cells were incubated for another 24 hours.

\section{Flow cytometric analysis}

Flow cytometric analysis of monocyte and DC specific surface antigens was performed on a FACSCalibur flow cytometer (BD Biosciences). The following fluorescein isothiocyanate (FITC) or phycoerythrin (PE) conjugated mouse anti-human monoclonal antibodies were used for direct labeling of the cells: antiCDla-PE (clone BL6), antiCD14-FITC (RMO52), both from Beckman-Coulter, Krefeld, Germany. Isotype matched monoclonal antibodies of irrelevant specificity were used as controls.

\section{Allogenic mixed lymphocyte reaction}

The $\mathrm{T}$ cell stimulatory capacity of monocyte derived dendritic cells generated in the presence or absence of dust extract was determined by measuring induction of interferon $\gamma$ (IFN- $\gamma$ ) in an allogenic mixed lymphocyte reaction. $1 \times 10^{4}$ monocyte derived dendritic cells were incubated with $1 \times 10^{5}$ allogenic lymphocytes in a 96-well flat bottom cell culture plate (Nunc, Wiesbaden, Germany) for 96 hours in CTCM. Concentrations of IFN- $\gamma$ were assessed in cell free supernatants by ELISA (IFN- $\gamma$ OptEIA Set, BD Biosciences).

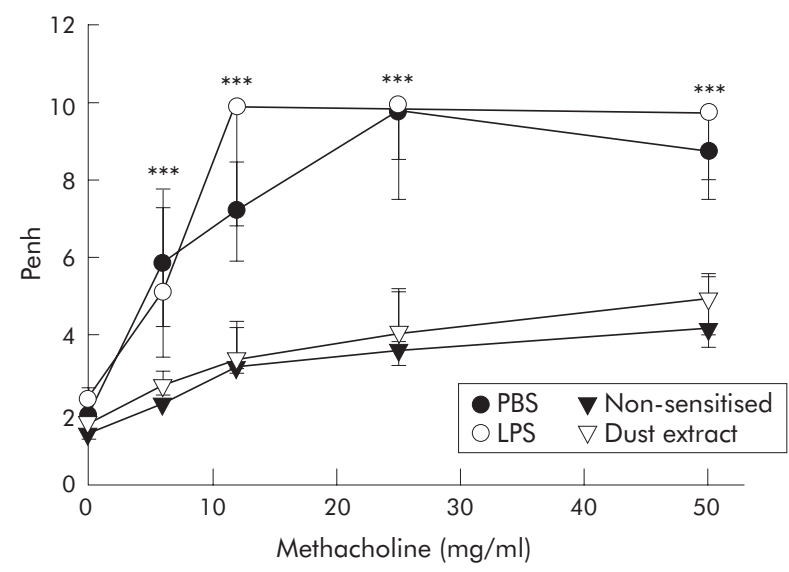

Figure 2 Airway responsiveness following exposure to stable dust extract during sensitisation. Airway responsiveness to methacholine was measured 24 hours after the second challenge with ovalbumin (OVA) in mice treated by inhalation of dust extract $(n=16)$ or sham treated with phosphate buffered saline (PBS; $n=16$ ) during sensitisation. Another control group was treated during sensitisation by inhalation of lipopolysaccharide (LPS) as a matched control to LPS content of dust extract $(n=8)$. Median Penh values from groups of mice were related to the methacholine concentrations used for provocation. Whiskers represent the $25-75$ th percentile of median values. ${ }^{* * *} p<0.001$ dust extract treated mice $v$ PBS treated mice.

\section{Statistical analysis}

Statistical analysis was performed to test whether treatment with dust extract leads to a significant reduction in several parameters associated with allergic disease. For this purpose, data from the mouse model were analysed by the two tailed Mann-Whitney test. In vitro studies with human leucocytes were analysed by the two tailed Wilcoxon matched pairs test. Graph Pad Prism Software (Version 3.03) was used for analysis. Values of $\mathrm{p}<0.05$ were considered statistically significant. All results are presented as median with 2575th percentile in parentheses.

\section{RESULTS}

\section{Effect of treatment with stable dust extract on AHR}

Following sensitisation and challenge with OVA, the mice developed marked AHR compared with non-sensitised controls (fig 2). To examine the influence of stable dust on allergen induced AHR, mice were exposed to an aerosol of dust extract during sensitisation and first challenge. Mice treated with dust extract were nearly as unresponsive to methacholine provocation as non-sensitised mice. In contrast, treatment of mice with a solution containing $0.8 \mu \mathrm{g} / \mathrm{ml}$ $E$ coli LPS as a matched control to the LPS content of dust extract did not reduce AHR. Treatment of non-sensitised mice with dust extract did not induce changes in airway reactivity (data not shown).

\section{Suppression of airway eosinophilia following treatment with stable dust extract}

In addition to AHR, allergic asthma is characterised by airway inflammation with predominant infiltrates of eosinophils. As shown in fig 3, the BAL fluid of non-sensitised mice contained only moderate numbers of macrophages, no lymphocytes, and no eosinophils. After sensitisation and challenge with OVA, eosinophils (primarily) and also lymphocytes and macrophages were recruited to the airways to give BAL fluid levels of $9.6 \times 10^{5}\left(7.6-11.5 \times 10^{5}\right)$ eosinophils and $1 \times 10^{5}\left(0.8-1.1 \times 10^{5}\right)$ lymphocytes. Treatment of

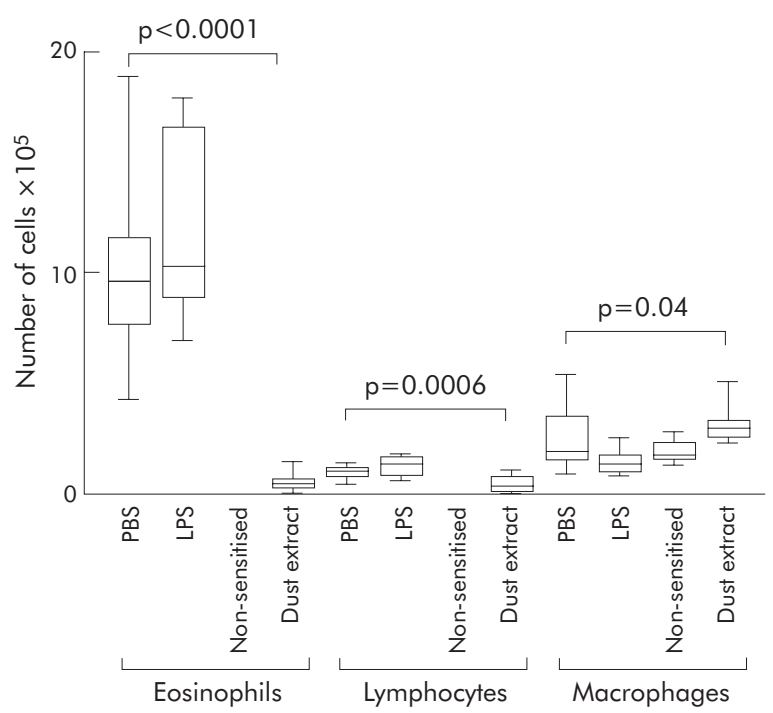

Figure 3 Effect of exposure to stable dust extract on allergen induced airway inflammation. Total number of eosinophils, lymphocytes and macrophages in BAL fluid recovered from mice treated by inhalation of dust extract $(n=16)$ or sham treated with phosphate buffered saline (PBS, $n=16$ ) during sensitisation were counted and differentiated to evaluate recruitment of leucocytes to the airways. Another control group was treated during sensitisation by inhalation of lipopolysaccharide (LPS) as a matched control to the LPS content of dust extract $(n=8)$. Boxes represent the 25-75th percentiles, horizontal lines represent median values; whiskers show the highest and lowest values. 
Table 1 Effect of inhaled dust extract on IL-5 and IL-10 production of murine splenocytes

\begin{tabular}{lll}
\hline Treatment & IL-5 (pg/ml) & IL-10 (pg/ml) \\
\hline PBS & $834(625.5-1002)$ & $1459(1164-1782)$ \\
LPS & $1080(806.5-1420)$ & $1816(1482-2030)$ \\
Dust extract & $309(248-402.3)$ & $1275(842.8-1742)$ \\
& $p<0.0001$ & $p=0.4398$ \\
Non-sensitised & $5.2(0-16.5)$ & $91.5(78-124)$ \\
\hline
\end{tabular}

IL, interleukin; PBS, phosphate buffered saline; LPS, lipopolysaccharide. In vitro production of IL-5 and IL-10 was measured by ELISA after restimulation of splenocytes with OVA for 2 days; $n \geqslant 8$ per group. Results are presented as median with 25-75th percentile in parentheses. Dust extract treated mice were compared with PBS treated mice by the two tailed Mann-Whitney test.

mice with LPS did not have any significant effect on cell recruitment to the airways induced by sensitisation and challenge. In contrast, treatment with stable dust extract led to a significant suppression of eosinophil and lymphocyte recruitment to the airways, with BAL fluid levels of $0.4 \times 10^{5}$ $\left(0.2-0.7 \times 10^{5}\right)$ eosinophils and $0.3 \times 10^{5}\left(0.2-0.7 \times 10^{5}\right)$ lymphocytes.

\section{Influence of treatment with dust extract on production of Th 2 cytokines}

Airway eosinophilia is dependent on the secretion of Th2 type cytokines, especially IL-5, from Th2 lymphocytes as a consequence of allergic sensitisation. ${ }^{15}$ Accordingly, sensitisation caused induction of Th2 cytokines with increased in vitro production of IL-5 and IL-10 in splenocyte cultures restimulated with OVA (table 1). However, in vitro production of IL- 5 by splenocytes from sensitised and dust treated mice was reduced by about $63 \%$ compared with sensitised mice sham treated with PBS. Treatment with LPS, however, did not result in a significant reduction in sensitisation induced IL-5 production but tended to increase IL-5 concentrations in vitro. Production of IL-10 did not seem to be affected by inhalation of dust extract.

\section{Influence of stable dust extract on development of humoral immune responses to allergens}

Serum levels of OVA specific $\operatorname{IgG}_{1}$ and IgE antibodies increased substantially after sensitisation (table 2). Following treatment with dust extract during sensitisation, the production of both OVA specific $\operatorname{IgG}_{1}$ and $\operatorname{IgE}$ was reduced compared with mice sham treated with PBS during sensitisation. Inhalation of LPS during sensitisation did not have any significant effect on the production of either antibody isotype. Interestingly, OVA specific $\operatorname{IgG}_{2 a}$ antibodies, which are associated with Thl responses and which were only marginally but significantly increased in the serum after sensitisation and challenge, did not increase in concentration following treatment with dust extract.

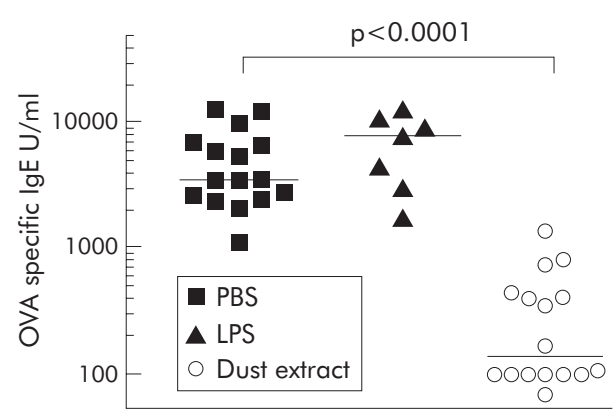

Figure 4 Effect of dust extract inhalation on allergen specific lgE levels in the airways. BAL fluid was collected following sensitisation to OVA and two OVA aerosol challenges. Concentrations of OVA specific lgE antibodies were measured by ELISA. Individual values expressed as arbitrary units and median values are shown. No OVA specific lgE was detected in non-sensitised mice (data not shown).
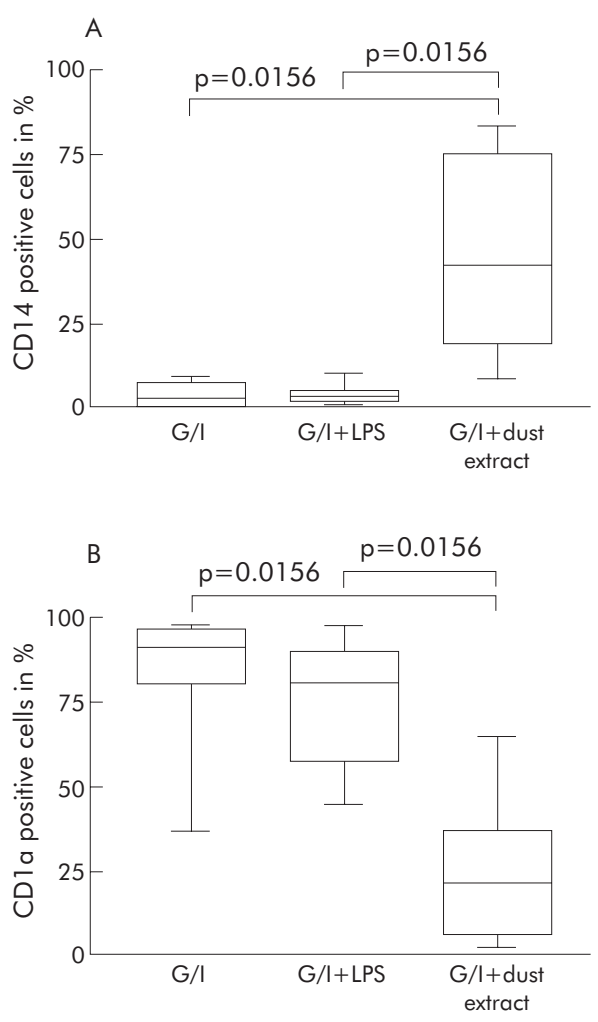

Figure 5 Surface expression of CD1 4 and CDla on monocyte derived dendritic cells. Peripheral blood monocytes from six donors were cultured for 7 days with GM-CSF and IL-4 (G/I), GM-CSF/IL-4 and LPS (G/I + LPS), or GM-CSF/IL-4 and dust extract (G/I + dust extract). Resulting cells were evaluated by FACS for expression of (A) CD14 and (B) CD la. Boxes represent the 25-75th percentiles, horizontal lines represent median values; whiskers show the highest and lowest values.

Table 2 Effect of inhaled dust extract on serum antibody production in mice

\begin{tabular}{|c|c|c|c|}
\hline Treatment & $\begin{array}{l}\lg \mathrm{E} \\
\left(\times 10^{5} \mathrm{U} / \mathrm{ml}\right)\end{array}$ & $\begin{array}{l}\lg G_{1} \\
\left(\times 10^{5} \mathrm{U} / \mathrm{ml}\right)\end{array}$ & $\begin{array}{l}\lg _{2 a} \\
\left(\mathrm{OD}_{405}\right)\end{array}$ \\
\hline PBS & $2.7(1.7-5.6)$ & $11.1(8.1-19.6)$ & $0.15(0.13-0.27)$ \\
\hline LPS & $2.2(1.3-5.6)$ & $13.3(8.4-26.7)$ & $0.14(0.13-0.3)$ \\
\hline Dust extract & $1.3(0.9-2.0), p=0.017$ & $5.5(2.0-8.1), p=0.001$ & $0.17(0.13-0.2)$ \\
\hline Non-sensitised & 0 & 0 & 0.09 \\
\hline
\end{tabular}

PBS, phosphate buffered saline; LPS, lipopolysaccharide.

Serum levels of OVA specific $\lg E_{1} \lg G_{1}, \lg G_{2 a}$ were measured by ELISA and expressed as arbitrary units; $n \geqslant 8$ per group. The results are presented as median with the 25-75th percentile in parentheses. Dust extract treated mice were compared with PBS treated mice by the two tailed Mann-Whitney test. 
To determine local antibody responses in the airways during allergic inflammation, OVA specific IgE was also measured in BAL fluid. ${ }^{16}$ IgE titres in sensitised and sham treated mice were significantly higher than in non-sensitised mice which did not have any detectable OVA specific antibodies in BAL fluid. Inhalation of dust extract significantly reduced IgE titres in BAL fluid (fig 4) while treatment with LPS had no significant effect.

\section{Reduced T cell stimulatory capacity of human dendritic cells generated in the presence of stable dust extract}

Allergen induced airway inflammation and AHR are thought to depend on $\mathrm{T}$ cell responses. $\mathrm{T}$ cells in turn require activation by specialised antigen presenting dendritic cells. To determine whether dendritic cell differentiation can be inhibited by substances present in the dust extract, we tested the influence of the extract on in vitro generation of monocyte derived dendritic cells.

Monocytes isolated from human blood were cultured in the presence of GM-CSF and IL-4 for 7 days resulting in dendritic cell differentiation as demonstrated by expression of CDla and downregulation of CDl4 (fig 5). The presence of $2 \mathrm{ng} / \mathrm{ml}$ $E$ coli LPS (concentration matched to LPS concentration in dust extract) during culture did not seem to have an influence on dendritic cell differentiation with respect to upregulation of CDla and downregulation of CD14. In contrast, the presence of dust extract inhibited the GM-CSF and IL-4 (G/I) induced differentiation of monocytes, reducing upregulation of CDla while partially maintaining CDI4 expression. These incompletely differentiated cells had a reduced $\mathrm{T}$ cell stimulatory capacity in allogenic mixed lymphocyte reactions as measured by IFN- $\gamma$ release. In the presence of cells differentiated with dust extract, IFN- $\gamma$ production was significantly reduced by $37.1 \%$ compared with IFN- $\gamma$ concentrations in mixed lymphocyte reactions with monocyte derived dendritic cells generated in the absence of dust extract $(\mathrm{G} / \mathrm{I}=7.0 \mathrm{ng} / \mathrm{ml}$ (5.5-32.9); G/I+ dust extract $=4.4 \mathrm{ng} / \mathrm{ml} \quad(1.2-15.1) ; \mathrm{n}=6 ; \mathrm{p}=0.03)$. Monocyte derived dendritic cells from matched LPS control cultures did not significantly change IFN- $\gamma$ production in mixed lymphocyte reactions (G/I+LPS $=6.6 \mathrm{ng} / \mathrm{ml}$ 19.1), not significant $(p=0.16)$ versus $G / I)$.

\section{DISCUSSION}

In this study we present evidence that dust collected from stables of traditional farms contains biologically active factors which, after extraction with physiological sodium chloride solution and administration by inhalation, can protect mice from allergic sensitisation, eosinophilic airway inflammation, and resulting AHR. This is the first experimental approach to confirm the epidemiological observation that exposure to the stable environment of traditional farms reduces the risk of allergic diseases. ${ }^{1-4}$

The method used in our study to extract substances from stable dust is likely to be comparable to the natural situation in the bronchial mucosa where salt containing mucosal fluid probably extracts similar substances from inhaled stable dust particles. The effect of dust extract inhalation was particularly strong on AHR and airway inflammation, while the protective activity of inhaled dust extract on systemic sensitisation was less pronounced. Mean antibody titres $\left(\operatorname{IgG}_{1}\right.$ and $\operatorname{IgE}$ ) in the serum of mice treated with dust extract were only slightly reduced. This indicates that inhaled dust extract mainly acts locally in the airways, inhibiting the effects of airway allergen challenges and, to a lesser extent, the systemic responses to intraperitoneal sensitisation with OVA and aluminum hydroxide. This interpretation is further supported by the observation that, in contrast to serum levels, local concentrations of OVA specific IgE in BAL fluid were markedly reduced after dust extract inhalation. These findings indicate that the anti-allergic effects of dust extract would be even more pronounced in a model of sensitisation exclusively via the airways. Such a model may reflect allergen sensitisation in infants more closely than intraperitoneal hyperimmunisation used in this study.

Several authors have observed similar reductions in airway symptoms after treatment with solutions of microbes or microbial compounds. Broide et al showed that bacterial CpGoligodeoxynucleotides led to suppression of allergen induced asthma in mice, and Hopfenspirger et al found that treatment with mycobacterial antigens could attenuate allergen induced airway eosinophilia and deterioration of lung function even in mice with established allergic airway inflammation. ${ }^{7} 811$ 17-19 Furthermore, there is a body of information regarding the effects of LPS in mouse models of asthma which shows that systemic treatment with LPS in relatively high doses results in at least partial reduction of allergic symptoms. ${ }^{78}$ In all of these experiments LPS seemed to induce a shift towards Thl responses. This is in contrast to our findings of slight enhancement of Th2 responses following LPS treatment and a lack of Thl response after inhalation of stable dust extract. This difference may be due to the comparatively low concentration of LPS in stable dust extract and the matched LPS concentration used in our control experiments. It has been shown previously that low concentrations of LPS are not only unable to inhibit allergic sensitisation and Th2 responses, but that they can even enhance these. ${ }^{8}$ Although the endotoxin concentration in dust extract is too low to inhibit sensitisation of mice, we cannot exclude the possibility that it acts synergistically with other immune modulatory substances of farm dust as Roy et $a l^{20}$ have shown for IL-10 and IL-12 release of human peripheral blood mononuclear cells after stimulation with barn dust DNA in vitro.

Considering the lack of a Thl shift, it is likely that the immune modulation induced by stable dust extract was based on the induction of immunological tolerance or suppression. This hypothesis is supported by our results showing that human monocyte derived dendritic cells generated in the presence of dust extract showed a much weaker $\mathrm{T}$ cell stimulatory capacity than those generated without dust extract. This lack of stimulatory capacity was associated with persistent CDI4 and reduced CDla expression, indicating incomplete differentiation from monocytes into dendritic cells in the presence of dust extract. The stable dust extract may therefore exert an influence on allergic immune responses by modulating differentiation and function of antigen presenting cells (APC). It is tempting to speculate that modulation of APC differentiation by components of stable dust may lead to unresponsiveness of allergen specific T cells. Although we do not present direct evidence for this hypothesis, our data indicate downregulation of the $\mathrm{T}$ cell response rather than activation.

Finally, the finding that stable dust extract used in our study contained immune modulatory substances which were able to inhibit the development of allergic sensitisation, eosinophilic airway inflammation, and changes in lung function could lead the way to new prophylactic treatments for the prevention of allergic diseases. In particular, the observation that inhalation of stable dust extract resulted in suppression or unresponsiveness rather than induction of Thl responses against the allergen makes stable dust derived compounds interesting candidates for therapeutic approaches in humans, since the lack of Thl induction may reduce the risk of undesirable side effects such as autoimmunity. ${ }^{21}$

In summary, we have established an experimental schedule which will allow the identification of relevant 
biologically active compounds in the inhaled stable dust extract. Using this experimental schedule, our study shows that it is possible to extract highly active substances from stable dust which can suppress sensitisation in a mouse model of allergic asthma. The priority now is to define the active factors in stable dust and to establish their precise mode of action.

\section{ACKNOWLEDGEMENTS}

The authors are indebted to their collaborators in the ALEX Study Group (David Carr and Rudolf Schierl, Munich, Germany; Waltraud Eder, Tucson, USA; Udo Herz and Harald Renz, Marburg, Germany; Roger P. Lauener, Zurich, Switzerland; Marco Waser, Basel, Switzerland) and thank Britta Steeger, Petra Fritz, Petra Behrens, and Erika Flacke for excellent technical assistance.

\section{Authors' affiliations}

M Peters, M Kauth, A Bufe, Department of Experimental Pneumology, Ruhr-University Bochum, Bochum, Germany

O Holst, Division of Structural Biochemistry, Forschungszentrum Borstel, Leibniz-Center for Medicine and Biosciences, Borstel, Germany

J Schwarze, Department of Respiratory Medicine, National Heart and Lung Institute, Imperial College, London, UK

J Schwarze, C Körner-Rettberg, Klinik für Kinder- und Jugendmedizin, St Josef-Hospital, Bochum, Germany

J Riedler, Kinderspital Schwarzach, Schwarzach, Austria

D Nowak, Institute of Occupational and Environmental Medicine,

University of Munich, Munich, Germany

C Braun-Fahrländer, Institute of Social and Preventive Medicine, Basel, Switzerland

E von Mutius, Dr von Hauner Children's Hospital, Munich, Germany

This study was supported by grants from the Deutsche Forschungsgemeinschaft (DFG: BU-762/5-1, HO-1259/4-1).

Competing interests: none.

MP and MK contributed equally to the manuscript.

\section{REFERENCES}

1 Riedler J, Braun-Fahrländer C, Eder W, et al. Exposure to farming in early life and development of asthma and allergy: a cross-sectional survey. Lancet 2001;358:1129-33.

2 Braun-Fahrländer C, Riedler J, Herz U, et al. Environmental exposure to endotoxin and its relation to asthma in school-age children. N Engl J Med 2002;347:869-77.
3 Von Ehrenstein OS, von Mutius E, Illi S, et al. Reduced risk of hay fever and asthma among children of farmers. Clin Exp Allergy 2000;30:187-93.

4 van Strien RT, Engel R, Holst O, et al. Microbial exposure of rural school children, as assessed by levels of $\mathrm{N}$-acetyl-muramic acid in mattress dust, and its association with respiratory health. J Allergy Clin Immunol 2004; 113:860-7.

5 Gerhold K, Blümchen K, Franke A, et al. Exposure to endotoxin and allergen in early life and its effect on allergen sensitization in mice. J Allergy Clin Immunol 2003;112:389-96.

6 Gerhold K, Blümchen K, Bock A, et al. Endotoxins and allergy: lessons from the murine model. Pathobiology, 2002-, 2003;70:255-9.

7 Gerhold K, Blümchen K, Bock A, et al. Endotoxins prevent murine lgE production, $T(H) 2$ immune responses, and development of airway eosinophilia but not airway hyperreactivity. J Allergy Clin Immunol 2002;110:110-6.

8 Eisenbarth SC, Piggott DA, Huleatt JW, et al. Lipopolysaccharide-enhanced, toll-like receptor 4 -dependent T helper cell type 2 responses to inhaled antigen. J Exp Med 2002; 196:1645-51.

9 Romagnani S. The increased prevalence of allergy and the hygiene hypothesis: missing immune deviation, reduced immune suppression, or both? Immunology 2004; 1 12:352-63.

10 Zuany-Amorim C, Sawicka E, Manlius C, et al. Suppression of airway eosinophilia by killed Mycobacterium vaccae-induced allergen-specific regulatory T cells. Nat Med 2002;8:625-9.

11 Liu YH, Kao MC, Lai YL, et al. Efficacy of local nasal immunotherapy for Dp2induced airway inflammation in mice: Using Dp2 peptide and fungal immunomodulatory peptide. J Allergy Clin Immunol 2003;1 12:301-10.

12 Tomkinson A, Cieslewicz G, Duez C, et al. Temporal association between airway hyperresponsiveness and airway eosinophilia in ovalbumin-sensitized mice. Am J Respir Crit Care Med 2001; 163:721-30.

13 Hamelmann E, Schwarze J, Takeda K, et al. Noninvasive measurement of airway responsiveness in allergic mice using barometric plethysmography. Am J Respir Crit Care Med, 1997;156:766-75.

14 Sallusto F, Lanzavecchia A. Efficient presentation of soluble antigen by cultured human dendritic cells is maintained by granulocyte/macrophage colony-stimulating factor plus interleukin 4 and downregulated by tumor necrosis factor alpha. J Exp Med 1994;179:1109-18.

15 Hamelmann E, Cieslewicz G, Schwarze J, et al. Anti-interleukin 5 but not anti$\lg \mathrm{E}$ prevents airway inflammation and airway hyperresponsiveness. Am J Respir Crit Care Med 1999;160:934-41.

16 Chvatchko Y, Kosco-Vilbois MH, Herren S, et al. Germinal center formation and local immunoglobulin $\mathrm{E}(\mathrm{lgE})$ production in the lung after an airway antigenic challenge. J Exp Med 1996;184:2353-60.

17 Broide D, Schwarze J, Tighe H, et al. Immunostimulatory DNA sequences inhibit IL-5, eosinophilic inflammation, and airway hyperresponsiveness in mice. J Immunol 1998;161:7054-62.

18 Hopfenspirger MT, Agrawal DK. Airway hyperresponsiveness, late allergic response, and eosinophilia are reversed with mycobacterial antigens in ovalbumin-presensitized mice. J Immunol 2002;168:2516-22.

19 Saito K, Yajima T, Nishimura H, et al. Soluble branched beta- $(1,4)$ glucans from Acetobacter species show strong activities to induce interleukin-12 in vitro and inhibit T-helper 2 cellular response with immunoglobulin $\mathrm{E}$ production in vivo. J Biol Chem 2003;278:38571-8.

20 Roy SR, Schiltz AM, Marotta A, et al. Bacterial DNA in house and farm barn dust. J Allergy Clin Immunol 2003;1 12:571-8.

21 Stephens R, Eisenbarth SC, Chaplin DD. Thelper type 1 cells in asthma: friend or foe? Curr Opin Allergy Clin Immunol 2002;2:31-7. 